The Competing-risk Analysis of post-IPO Delistings

Jun Chen*

Ronald Rutherford**

Peiming Wang***

November 2010

* Department of Finance, Faculty of Business and Law, Auckland University of Technology, Auckland 1142, New Zealand. E-mail: jun.chen@aut.ac.nz

** Department of Finance, Lykes Chair of Finance and Sustainability, College of Business, University of South Florida, 4202 East Fowler Avenue, BSN 3403, Tampa, FL 33620-5500. E-mail: rrutherford@usf.edu

Department of Finance, Faculty of Business and Law, Auckland University of Technology, Auckland 1142, New Zealand. E-mail: peiming.wang@aut.ac.nz 


\section{The Competing-risk Analysis of post-IPO Delistings}

This paper is working on one IPO panel data to estimate the predicting power of some covariates on future status of IPO firms after going public. Specifically, our study aims to study how the possibility of the delisting due to different reasons, including merges, moves between exchanges, and bad performance (liquidation/Bankruptcy), is affected by those covariates. The results show that the inclusion of the aftermarket performance in a competing risk model helps to distinguish the impact of those covariates on the delistings caused by three events. There are three main results from our analysis. First, it is found that most of covariates have significant effects on two types of delistings, mergers- and failure-originated. On the other side, only firm size and capital structure are related to the delisting when the IPO firm switches to another exchange. Second, we find that some covariates have significant effects on two delistings, acquisition/merger- or liquidation/bankruptcy-originated, in the same direction, including technology dummy, IPO activity, firm age, asset growth, R\&D expenses, and leverage. Third, three covariates, including venture capital dummy, profitability, and firm size, have opposite effect on different events triggering the delisting, mergers and bad performance. The increase of these covariates could increase the risk of acquisition/merge delisting whereas reduce the risk of failure delisting. 


\section{The Competing-risk Analysis of post-IPO Delistings}

\section{Introduction}

Our study is attempting to assess post-IPO delisting due to different reasons based on the information provided by IPO deal-related characteristics at the IPO time and accounting covariates, which are updated periodically after going public. The assessment of delisting possibility is of significant importance for investors who are interested in the IPO firms since such assessment can help make the correct decision whether or not to adjust their portfolios if related to the new firms.

We classify all the delistings into three groups according to their reasons, which triggered the delistings. The information on all the delisting reasons is provided by the CRSP delisting codes. Based on delisting codes, there are four categories of aftermarket status of new firms after going public, including "active", "delisted due to acquisition/merge", "delisted due to moves to different exchanges", and "delisted due to bad performance". Here, we also refer bad performance as liquidation or bankruptcy.

It is not uncommon to observe a firm to be delisted after the initial public offering (IPO). Since delistings may be triggered by many events, including merger/acquisition, migration to another exchange, liquidation, and bankruptcy, these potential reasons for delistings are defined as competing risks. These events are competing because the one which occurs first causes the delisting of IPO firms, preventing other events from happening completely. For example, a firm can not default if it has already been delisted because of an acquisition. Therefore, when we are assessing delisting risk generated by a specific event of interest, it is necessary to control for the effect of other competing-risk 
events simultaneously because of the interdependence among the possibilities of multiple cause-specific delistings.

The current IPO literature has focused the most attention on predicting the future states of firms after the IPO, using the data available before the IPO or at the IPO date. Several papers find that a set of variables, such as firm size and age, can be used to forecast whether the IPO firm survives or delists. There exists little or no evidence examining the competing reasons for IPO delisting. Also, the use of post-IPO financial data has not received much attention in examining the specific delisting reasons. We suggest that the post-IPO multi-period financial data might be helpful in explaining the competing rationale for delisting.

The most widely used method to deal with competing-risk dataset, proposed by Kalbfleisch and Prentice (1980), is to estimate model separately for each type of failure while treating the different events as censored data. However, Lunn and McNeil (1995) argue that one drawback of the Kalbfleisch and Prentice (1980) method is that it doesn't treat the different risks jointly. Therefore, in this paper, we implement the method proposed by Fine and Gray (1990) to fit a competing risk model to a panel data of initial public offerings consisting of 4,546 IPOs from 1975 through 2006.

By taking in competing-risk events account to describe the effect of covariates on post-IPO delistings due to the three reasons, our study contributes to the current literature on IPO failure risk in two aspects. First, we apply the competing-risk model to the IPO panel data, which including both IPO-deal related properties at the IPO date and annually updated accounting information after going public. To our understanding, such analysis has yet been done. The competing risk analysis on the IPO panel data is able to help 
predicting the possibility of delisting due to different reason more precisely, in terms of both the algorithm of duration model and the amount of information.

Second, the reasons for post-IPO delistings are classified into three main groups according the delisting codes, including acquisition/merger, move to another exchanges, and liquidation/bankruptcy. Since the prior literature always divided the delisting events to two groups by combining takeover with move between exchanges, some information may have been missed. Differently speaking, it is possible for investors to retrieve different information out of two different events, acquisition/merger and move to another exchange. Therefore, a more detailed classification of competing-risk events can improve our understanding about how post-IPO delistings are determined.

The results show that, by including the aftermarket annual accounting information, competing risk model can help distinguish the impact of those covariates on the delistings due to three different reasons. There are three main results out of our analysis. First, it is found that most of covariates have significant effects on delistings due to both acquisition/merger and liquidation/bankruptcy, whereas only two factors, firm size and capital structure, are related to the delisting triggered by the switches of IPO firm from one exchange to another. Second, we find that some covariates have significant effects on two delistings, acquisition/merger- or liquidation/bankruptcy-originated, in the same direction, including technology dummy, IPO activity, firm age, asset growth, R\&D expenses, and leverage. Third, three covariates, including venture capital dummy, profitability, and firm size, have opposite effect on different events triggering the delisting, acquisition/merger and liquidation/bankruptcy. The increase of these covariates 
could increase the possibility of delisting generated by acquisition/merge but reduce the risk of delisting due to failure, either liquidation or bankruptcy.

\section{Literature review}

The delisting risk, also called as failure risk, has been a hot topic under studies so far. Many researchers suggest that some information available before the issuance or at the IPO date is related to the future state of the firm after going public. For example, Hensler, Rutherford, and Springer (1997) find that the survival time for IPOs increases with some firm properties, including firm size, age of the firm at the offering, the initial return, IPO activity level in the market, and the percentage of insider ownership. Their results of duration models also show that survival is negatively related to other factors such as the number of risk characteristics.

Fama and French (2004) investigate the characteristics of new firms listed on major U.S. stock markets from 1973 to 2001 and find that both declining profitability and increasing growth lead to more IPO firms delisted due to bankruptcy, but have no impact on the possibility of IPO firm delisted due to acquisition/merge. Therefore, their results imply that both profitability and growth could be good candidates to distinguish between the survival and failure of IPO firms.

Howton (2006) studies the relationship between firm's governance characteristics and the post-IPO state. His results show that IPO firms that are venture-backed, have a CEO who is the original firm founder, have an outside block holder present, use a more reputable underwriter, and have a more stable board directors are more likely to survive than be acquired in the first five years after the IPO whereas a larger percentage of grey 
directors on the board are associated with IPO firms that are more likely to fail. His analysis is performed by fitting one Logistic regression between each pair of three future states after going public, consisting of "survive", "delisted due to takeover", and "delisted due to failure".

Demers and Joos (2007) study the survival rate of IPO firms by including IPOdeal characteristics and accounting information at the IPO time. The information that they used to predict the survival rate of IPOs is available around the issuing date. Moreover, they find that the possibility of IPO failure estimated by logit model is negatively associated with one-year post-IPO abnormal returns. In other words, the information on IPO failure is not complete at the IPO date, implying that more post-IPO information is necessary for a more precise estimate of IPO failure.

However, very few studies among the IPO literatures has attempted to assess the delisting risk by using the post-IPO accounting information over multiple periods after going public in the duration models. Therefore, it is of interest to examine whether or not including the aftermarket accounting numbers improves the predictability of duration models on the future status after going public.

\section{Determinants and Methodology}

\subsection{Determinants of IPO delistings}

In this study we examine how the likelihood of post-IPO delistings due to three different reasons is determined. Following the current prior IPO literature, we consider two sets of covariates as potential determinants: fixed and time-varying. For example, Demers and Joos (2007) include IPO-deal characteristics as fixed determinants, 
composed of technology dummy, venture-backed dummy, under-pricing, IPO proceeds, and number of IPO per quarter. These covariates are defined as fixed since their values will remain unchanged once the issue has been finished at the IPO time. They also include the accounting determinants in their models to predict the IPO failure risk. However, they only estimate their models based on the accounting information over single-period around the issuing time. In other words, the information contained by annual financial statements after going public has not been taken into account in their study.

Unlike Demers and Joos (2007), we are attempting to check the link between the delisting possibility and the determinants by adding the post-IPO financial accounting information, which are updated annually after going public, as time-varying determinants. This group includes firm age, firm size, profitability, growth, research and development expenses, selling, general, and administrative expenses, and leverage.

Many studies have shown that venture capital firms improve the aftermarket performance of IPO firms. For example, both Jain and Kini (2000) and Brav and Gompers (1997) argue that VC backed IPOs outperform non-VC backed firms, although the conclusion of the latter only holds when returns are weighted equally. Thus, we expect that VC-backed IPO firms are less likely to be delisted due to bad performance, either liquidation or bankruptcy, than non-VC backed IPO firms.

Howton (2006) finds that a venture-backed IPO firm is more likely to survive rather than delisting after a takeover, which can be explained by the post-IPO presence of the venture firm on the board, proposed by Brav and Gompers (1997). However, we should treat this statement with more caution since Howton (2006) doesn't take into 
account the existence of competing-risk event in his study. As we know, the incidence of competing-risk event depends on each other. In sum, it is hard to predict the effect of venture capital firms on the post-IPO delisting due to acquisition or merger.

The literature has shown that probability of post-IPO delisting, caused by either takeover or bad performance, will be affected by the fact whether the IPO firm belongs to technology or internet industries. For example, Howton (2006) argues that the IPO firm in a high technology industry is more likely to be acquired, but less likely to be failed when comparing to survive within the first five years after going public. We expect that an IPO firm in internet industry has a higher possibility to be delisted due to takeover but a lower one for the delisting due to bad performance.

The current literature has proposed two theories in order to interpret the issue of IPO underpricing. The first theory attributes the underpricing to investor's uncertainty while the second argue that the managers are using underpricing to signal the firm quality. In case of uncertainty theory, a positive coefficient estimate is expected for underpricing in the event of bad performance. If the signaling model holds, we may expect a negative estimate for underpricing since an IPO firm with good quality is more likely to survive than delisted, no matter how the delisting is triggered.

As proposed by Fama and French (2004), we expect that profitability should help reduce the risk of delisting triggered by bad performance, either liquidation or bankruptcy. Meanwhile, their study implies a positive association between growth of assets and failure rate. However, they argue that there is no significant of either variable on the delisting risk originated from acquisition/merges. 
Firm size has been proven to be a key issue when the firms are making decision on takeover or other issues. The prior literature has documented that a larger firm is more likely to survive because of a less default risk.

Following Demers and Joos (2007), we include R\&D expenses to capture the scale of firm's expenditures on R\&D. The effect of R\&D expenses on delisting risk could be either positive or negative. On one side, more R\&D expenses may provide more growth opportunity for the IPO firm, indicating a negative link between R\&D expenses and the delisting risk, i.e. R\&D expenses will reduce the possibility of IPO firms to be delisted after going public. On the other side, a higher level of R\&D expenses could imply the management inefficiency of the assets-in-place. Therefore, it is hard to predict the direction how R\&D expenses will affect the delisting risk due to different reasons.

The same story applies to another variable, selling, general, and administrative (SG\&A) expenses with the exception that SG\&A expenses are related to intangible assets. Again, the firm may benefit from more SG\&A expenses if the investment on intangible assets can create real future growth opportunity. Otherwise, a higher SG\&A expenses may do harm to firm's performance, leading a higher possibility of being delisted.

It has been documented that leverage plays an important role in predicting either the post-IPO status of new firm or the default risk of seasoned firm. Consistent with the findings in the prior studies, we expect a positive effect of leverage on the probability of delisting since a higher leverage would increase default risk, leading to more delistings.

Put all together, we include two sets of determinants in our competing-risk models, IPO deal-related characteristics, which are fixed at the IPO time, and aftermarket accounting variables, which are updated periodically. Therefore, there are multiple 
observations for each sample firm with time-varying accounting variables but fixed IPO deal-related properties.

\subsection{Methodology}

The most widely used method to deal with competing-risk dataset, proposed by Kalbfleisch and Prentice (1980), is to estimate model separately for each type of failure while treating the different events as censored data. However, Lunn and McNeil (1995) argue that one drawback of the Kalbfleisch and Prentice (1980) method is that it doesn't treat the different risks jointly. Instead, they suggest that a data duplication method can avoid such disadvantage. For example, all the observations of their cancer datasets are counted twice in the final sample to estimate the model, one for each type of failure risk.

Based on the method proposed by Fine and Gray (1999), we model the delisting rate due to reason $\mathrm{j}$ as subhazard defined as

$$
h_{j}(t \mid X)=\bar{h}_{j, 0}(t) \exp \left(X \beta_{j}\right)
$$

where $j=1,2$, and 3 for the acquisition/merger, the moves to another exchanges, and the bad performance, respectively. $X$ represents a set of variables, including fixed and time varying covariates. $\beta_{j}$ denotes the effect of covariates on the subhazard function caused by the $j^{\text {th }}$ reason. $h_{j}(t)$ is the instantaneous probability that a new list is delisted for reason $j$ conditional on that it is delisted first time since its listing. In the following analysis, the competing risk models are estimated using the Stcrreg package in STATA, which implements the method proposed by Fine and Gray (1999).

We also divide the full sample to subsamples based on firm size, measured by total assets (Equity) in this paper, and then, graph the Cumulative Incidence Function 
(CIF) of each competing-risk events for each firm-size groups. The firm with total assets lying below $70^{\text {th }}$ percentile is defined as small firm while the firm with total assets lying above $30^{\text {th }}$ percentile as large firm. The firm lying between $30^{\text {th }}$ and $70^{\text {th }}$ percentiles is classified as medium firms. The CIFs are computed based on the coefficient estimates from the competing-risk models for each cause-specific delisting, and the means of each variable within each firm size subgroup. By doing so, we can see how firm size affects the delisting risk due to different reasons for those typical firms of each firm size groups.

Table-1 defines all the variables used in this paper. The variables include the IPO deal-related characteristics, which are fixed at the IPO date once the issue has been finished, and the post-IPO financial data, which are time-varying.

[Table-1 about here]

\section{Data}

Our data collection originates from 8,464 IPOs from Jay Ritter's IPO data base from 1975 through 2006, containing founding date and first trading date for each firm. The information on the date of the issue, the dollar value of proceeds raised, and the percentage change in the stock price on the first trading day (under-pricing) are collected from Securities Data Company (SDC)'s Database. Following Fama and French (2003), our sample excludes REITs, closed-end funds, ADRs, unit offers, MLPs, and all issues with an offer price below 5 dollars. The SDC dataset covers the new issue in the United States from 1985 to 2008 . We obtain the annual financial data for these IPO firms from the CRSP and COMPUSTAT database. 
To be included in the final sample, the firms must have unique 6-digital CUSIP identification across JayRitter/SDC/CRSP/COMPUSTAT datasets to ensure the data availability of all the data required for our analysis. There are about $80 \%$ matches between CRSP and COMPUSTAT among the initial list of 8,464 IPO firms from Jay Ritter. Then, about 2,200 firms are deleted due to the mismatches between SDC and CRSP/COMPUSTAT and 4,546 firms remain in our final sample for survival analysis.

The aftermarket status of IPO firms is classified by their CRSP delisting codes. The firms are identified as "active" if their delisting codes are 100, "delisted due to acquisition/merge" if their delisting codes are in the 200 range, "delisted due to move to another exchanges" if their delisting codes are in the 300 range. The 200's indicate "acquired in merger" and the 300's indicate "issues acquired by exchange of stock". The firms are classified as "delisted due to bad performance" if their delisting codes are in the 400 range or 500 range, which we refer the bad performance as liquidation or bankruptcy. However, 55 firms whose delisting codes are from 501 to 520 and one with 575 are dropped from the final samples. Table-2 shows the status of all the remaining 4,547 IPO firms in the final sample.

\section{[Table-2 about here]}

There are 3,139 delistings among 4,547 IPO firms from 1975 to 2006, including 2,020 acquisition/merge delistings, 42 moves between exchanges delistings and 1,077 failure delistings. Consistent with Fama and French (2004), the number of IPO firms on major U.S. stock markets increases from the1970s to the post-1980 periods in general. Table-3 summarizes the data.

[Table-3 about here] 
Following Demers and Joos (2007), we adjust the value for those variables, which are measured in dollar amount, back to the value in 1973 dollar values according to the annual CPI growth rate, in order to get rid of the effect of inflation rate on our results. Such adjustment makes our results more comparable to the current IPO literature. The descriptive statistics of variable in our study is consistent with the previous studies such as Fama and French (2004) and Demers and Joos (2007).

The IPO firms have an average survival time of 66.11 months and underpricing of $5.35 \%$. It is interesting to find that the IPO firms are making $2.12 \%$ profit (measured by E/A) on average, with the exception of those bad performance delisted IPO firms, which are suffering a loss of $-4.43 \%$.

\section{Empirical results}

\subsection{Competing-risk model using the data within 5 years after IPO time}

Table-4 shows the results for the competing-risk model, using the IPO dealrelated characteristics and annually financial accounting data within 5 years after going public. The results are reported in Table-4.

\section{[Table-4 about here]}

It is worth noting that how each covariate affects the likelihood of post-IPO delisting depends on which event triggers the delisting status. Some variables have same impacts on three competing risk events in terms of the sign of coefficient estimates, whereas the others affect different events in different directions. There are three main findings based on the competing-risk analysis. 
First, we find that most of the coefficient estimates in the event of moves to another exchange are insignificant with two exceptions, equity and leverage. In other words, firm size and capital structure are positively related to the delisting risk due to shift of trading platform, implying that only equity and leverage can help predict the possibility of being delisted due to moves between exchanges. Differently speaking, a larger firm with more debt is more likely to switch between different trading platforms. However, the conclusion should be regard with more cautions since only 43 out of 4,547 IPO firms were delisted due to change of trading markets. It is recognized that more observations be necessary for a deeper understanding of the scenario.

Second, we find that some covariates have significant effects on two competingrisk events (acquisition/merger and liquidation/bankruptcy) in the same direction, including technology dummy, IPO activity, firm age, asset growth, R\&D expenses, and leverage.

Technology dummy has positive coefficients under both events, showing that an IPO firm in internet industry has a higher probability of post-IPO delisting, caused by either takeover or bad performance. However, our result differs from the current IPO studies such as Howton (2006), who finds that the IPO firm in a high technology industry is more likely to be acquired, but less likely to be failed when comparing to survive within the first five years after going public. The divergence may be attributed to the different ways how to treat the competing-risk events. Howton (2006) studies the competing-risk events by estimating the pair-wise Logistic regression, which may ignore the interdependence among competing-risk events. 
We also find that IPO activity is positively related to the likelihood of post-IPO delistings due to either reason. It is consistent with other studies such as Ritter (1990), who argues that the firms are attempting to raise capital when cost of equity is relatively low during the hot time. However, Hensler, Rutherford, and Springer (1997) find no evidence to support the timing effect on the delisting risk in their study.

Our results show that the coefficient estimates of firm age are negative for both reasons, implying that probability of delisting is inversely related to firm age. This conclusion is the same as those proposed by the prior literature, for example Schultz (1983) and Hensler, Rutherford, and Springer (1997). Specifically, the older firms are more likely to survive than delisting.

Table-4 also gives a positive coefficient estimate for the asset growth (dA/A), confirming the findings in Farm and French (2004). In other words, the new firms are more likely to be failed because of a high growth rate of total assets, which may be explained by overinvestment.

It is found that $R \& D$ expenses will increase the possibility of delisting due to either event based on our analysis. The positive link between R\&D expenses and delisting risk supports theory of the management inefficiency of the assets-in-place. It contraries to the findings in Demers and Joos (2007), who argue that a higher R\&D expenses means a higher growth opportunity for the IPO firm, indicating a negative link between $\mathrm{R} \& \mathrm{D}$ expenses and the delisting risk.

Consistent with the prior studies, we find a positive effect of leverage on the probability of delisting since a higher leverage would increase default risk, leading to more delistings. 
Third, three factors, including venture capital dummy, profitability, and firm size, have opposite effect on different events triggering the delisting, acquisition/merger and liquidation/bankruptcy. Specifically, the increase of these covariates could increase the risk of acquisition/merge delisting whereas reduce the risk of failure delisting.

For example, the coefficient estimate for the venture capital dummy is 0.27 in case of mergers related delisting risk with a -0.32 for delisting due to bad performance, either liquidation or bankruptcy. Thus, it can be concluded that a venture capital backed firm is more likely to delisted due to mergers rather than survive while less likely to be delisted due to bad performance.

However, our result is against the findings by Howton (2006), who finds that a venture-backed IPO firm is more likely to survive rather than delisting after a takeover. He attributes his findings to the argument, proposed by Brav and Gompers (1997), that the post-IPO presence of the venture firm on the board will reduce the delisting risk generated by a takeover. Our results prefer the opposite direction.

The same pattern is also found for profitability, indicating that a higher firm value will increase the possibility of IPO firms to be delisted caused by mergers, while reduce the risk of delisting resulting from a bad performance. Our result is consistent with that in Fama and French (2004), showing that profitability should help reduce the risk of delisting triggered by bad performance, either liquidation or bankruptcy. Meanwhile, their study implies a positive association between growth of assets and failure rate. However, they argue that there is no significant of either variable on the delisting risk originated from acquisition/merges. 
Firm size has been documented as a key issue when the firms are making decision on takeover or other issues. A larger firm is more likely to survive than delisted due to liquidation or bankruptcy because of a less default risk, which is supported our result. On the other side, we find that a larger firm is more likely to be involved in a takeover event.

Moreover, we find that some covariates only have effect on one event but not the other one, including underpricing, issuing proceeds, and SG\&A expenses. For example, underpricing has a positive coefficient estimate in case of takeover-originated delisting with an insignificant one for failure-triggered delisting. As we mentioned above, two theories have been suggested by the current literature to explain IPO underpricing, investor's uncertainty and signal of firm quality. The uncertainty one predicts a positive relationship between underpricing and delisting risk while the latter expects a negative link, no matter which reason triggered the delisting after going public. Our results support the theory of information asymmetry between firm and investors partially instead of signaling model.

The issuing proceeds has significantly negative coefficient estimate for bad performance case with an insignificant one for takeover case, implying that more issuing proceeds lead to a lower failure rate. The negative effect could be attributed the fact that more cash can protect the new firms from default risk.

On the other side, another variable, selling, general, and administrative (SG\&A) expenses is significantly positively related to bad performance triggered delisting without any impact on takeover triggered delisting. Since SG\&A expenses are related to intangible assets, a higher SG\&A expenses may do harm to an IPO firm's aftermarket performance, leading a higher possibility of being delisted. 
Put all together, we can find that factors have different impact on the delisting due to three different reasons. Therefore, it is very essential and helpful to consider competing-risk events help predict the future states of new firms after going public.

\subsection{Cumulative Incidence Function}

Figure-1 shows the results to compare the Cumulative Incidence Functions (CIF) between small, medium, and large firms in case of each competing risk event. The most advantage of this method is that the possibility of two delisting-triggering events can be compared directly across the post-IPO time period. An IPO firm is classified a small firm if the value of its total assets lies below the $70^{\text {th }}$ percentile while a large firm if the value of its total assets lies above the $30^{\text {th }}$ percentile. We use the mean values of the variables to graph the CIFs in each competing risk events in Figure-1.

[Figure-1 about here]

The pictures are showing the effect of firm size on the delisting risk due to various competing risk events. The upper panel of Figure-1 shows the CIF curves for different firm size groups in terms of delisting risk due to acquisition/merge. It can be seen that a typical large firm has a high cumulative possibility of being delisted due to takeover events than both medium and small firm. The small firm has the least possibility of being delisted because of takeover event.

The middle panel of Figure-1 shows the CIF curves of delisting risk due to moves between exchanges for three firm size groups. Again, we can see that a typical large firm has a highest cumulative possibility of being delisted due to shift between exchanges 
where a small firm has the least one. It should be noted that such delisting risk for both medium and small firms is very close to zero, compared to large firms.

The below panel of Figure-1 shows the CIF curves for different firm size groups in terms of delisting risk due to liquidation/bankruptcy. Differently from the above reasons, it can be seen that a typical small firm has a highest cumulative possibility of being delisted due to bad performance where a large firm has the least possibility of being delisted because of bad performance. Similar to the middle panel, we can find that that such delisting risk for both medium and large firms is very close to zero, compared to small firms.

In general, the picture of CIFs for individual competing-risk event shows how the firm size is affecting delisting risk because of three different reasons in a different way. Thus, our analysis may provide helpful instruction when the investors are making decision whether or not to invest their money in the IPO firms based on the public information available.

\section{Conclusion}

One IPO panel data is investigated to estimate the predicting power of some covariates on future status of IPO firms after going public. Specifically, our study aims to study how the possibility of the delisting due to different reasons, including merges, moves between exchanges, and bad performance (liquidation/Bankruptcy), is affected by those covariates. The results show that the inclusion of the aftermarket performance in a competing risk model helps to distinguish the impact of those covariates on the delistings caused by three events. 
There are three main results from our analysis. First, it is found that most of covariates have significant effects on two types of delistings, mergers- and failureoriginated. On the other side, only firm size and capital structure are related to the delisting when the IPO firm switches to another exchange. Second, we find that some covariates have significant effects on two delistings, acquisition/merger- or liquidation/bankruptcy-originated, in the same direction, including technology dummy, IPO activity, firm age, asset growth, R\&D expenses, and leverage. Third, three covariates, including venture capital dummy, profitability, and firm size, have opposite effect on different events triggering the delisting, mergers and bad performance. The increase of these covariates could increase the risk of acquisition/merge delisting whereas reduce the risk of failure delisting. 


\section{References}

Alon Brav, and Paul A. Gompers. (1997). "Myth or reality? The long-run underperformance of initial public offerings: Evidence from venture and non-venture capital-backed companies." Journal of Finance 52, 1791-1821.

Douglas A. Hensler, Ronald C. Rutherford, and Thomas M. Springer (1997). "The Survival of Initial Public Offerings in the Aftermarket." The Journal of Financial Research XX(1), 92-110.

Elizabeth Demers, and Philip Joos (2007). "IPO Failure Risk." The Journal of Accounting Research 45(2), 333-371.

Eugene F. Fama, and Kenneth R. French. (2004). "New lists: fundamentals and survival rates." The Journal of Financial Economics 73, 229-269.

Jason P. Fine, and Robert J. Gray. (1999). "A proportional hazards model for the subdistribution of a competing risk." The Journal of the American Statistical Association (94), 496-509.

Bharat A. Jain, and Omesh Kini. (2000). "Does the presence of venture capitalists improve the survival profile of IPO firms?" Journal of Business Finance and Accounting (27), 1139-1177.

Peter Thompson (2005). "Selection and Firm Survival: Evidence from the Shipbuilding Industry, 1825-1914." The Review of Economics and Statistics, 87(1): 26-36.

Shelly W. Howton. (2006). "The Effect of Governance Characteristics on the State of the Firm Following an IPO.” The Financial Review 41(3), 419-433. 
Table 1. Variable definitions

\begin{tabular}{ll}
\hline Variable name & Definition \\
\hline Survival time & Number of months traded on the exchanges after IPO \\
Failure & One if the firm delisted due to failure after IPO, zero otherwise \\
Acquisition/Merge & One if the firm delisted due to acquisition/merge after IPO, zero otherwise \\
Venture dummy & One if venture firm backed, zero otherwise \\
Technology dummy & One if high-technology firm, zero otherwise \\
Underpricing (\%) & Initial return for the first trading day \\
Proceeds (\$ millions) & Natural log of one plus Proceeds from the IPO in millions dollars \\
IPO activity & Number of IPOs per quarter \\
Age (years) & Natural log of one plus Firm age \\
Equity (\$ millions) & Natural log of one plus market value of common shares outstanding \\
E/A (\%) & Average percentage profitability \\
dA/A (\%) & Percent Growth in Assets \\
R\&D expense (\$ millions) & Natural log of one plus R\&D expense \\
SGA expenses (\$ millions) & Natural log of one plus selling, general, and administrative expenses \\
Leverage $(\%)$ & Total liabilities divided by total assets \\
\hline
\end{tabular}


Table 2: Status of IPO firms through 1975 to 2006

\begin{tabular}{|c|c|c|c|c|c|}
\hline IPO year & Total & Surviving & Merges & Move to Exchanges & Liquidation \& Bankruptcy \\
\hline 1975 & 3 & 0 & 3 & 0 & 0 \\
\hline 1976 & 11 & 1 & 8 & 0 & 2 \\
\hline 1977 & 6 & 0 & 5 & 0 & 1 \\
\hline 1978 & 10 & 1 & 6 & 1 & 2 \\
\hline 1979 & 20 & 2 & 12 & 0 & 6 \\
\hline 1980 & 40 & 7 & 15 & 2 & 16 \\
\hline 1981 & 108 & 12 & 57 & 4 & 35 \\
\hline 1982 & 42 & 7 & 17 & 4 & 14 \\
\hline 1983 & 255 & 27 & 121 & 13 & 94 \\
\hline 1984 & 108 & 17 & 43 & 5 & 43 \\
\hline 1985 & 108 & 8 & 62 & 5 & 33 \\
\hline 1986 & 201 & 37 & 106 & 3 & 55 \\
\hline 1987 & 148 & 21 & 82 & 0 & 45 \\
\hline 1988 & 57 & 10 & 27 & 0 & 20 \\
\hline 1989 & 68 & 16 & 37 & 0 & 15 \\
\hline 1990 & 61 & 18 & 30 & 0 & 13 \\
\hline 1991 & 144 & 36 & 72 & 0 & 36 \\
\hline 1992 & 237 & 54 & 121 & 0 & 62 \\
\hline 1993 & 304 & 82 & 146 & 0 & 76 \\
\hline 1994 & 258 & 61 & 135 & 0 & 62 \\
\hline 1995 & 271 & 57 & 155 & 0 & 59 \\
\hline 1996 & 427 & 98 & 218 & 0 & 111 \\
\hline 1997 & 307 & 84 & 139 & 1 & 83 \\
\hline 1998 & 178 & 55 & 70 & 1 & 52 \\
\hline 1999 & 342 & 123 & 137 & 1 & 81 \\
\hline 2000 & 273 & 112 & 114 & 2 & 45 \\
\hline 2001 & 54 & 28 & 18 & 0 & 8 \\
\hline 2002 & 46 & 28 & 16 & 0 & 2 \\
\hline 2003 & 47 & 34 & 10 & 0 & 3 \\
\hline 2004 & 134 & 107 & 25 & 0 & 2 \\
\hline 2005 & 141 & 129 & 11 & 0 & 1 \\
\hline 2006 & 137 & 135 & 2 & 0 & 0 \\
\hline Total & 4546 & 1407 & 2020 & 42 & 1077 \\
\hline
\end{tabular}




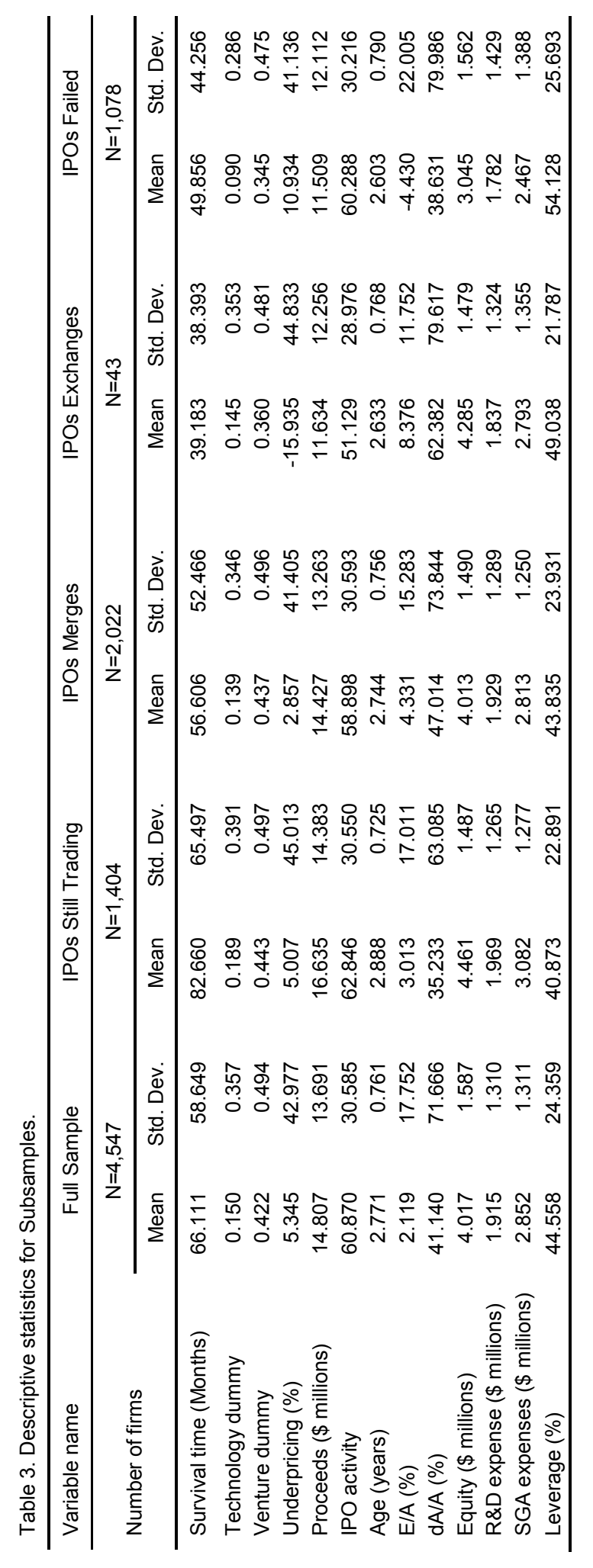


Table 4 Competing-risk Model Estimated Based on Information Including post-IPO Data

\begin{tabular}{|c|c|c|c|c|c|c|}
\hline \multirow{2}{*}{$\begin{array}{l}\text { Variable name } \\
\text { Technology dummy }\end{array}$} & \multicolumn{2}{|c|}{ Mergers (200-290) } & \multicolumn{2}{|c|}{ Exchanges $(300-390)$} & \multicolumn{2}{|c|}{ Bad Performance (400-599) } \\
\hline & -0.1884431 & ** & -0.9930925 & & -0.5280817 & $* * \star$ \\
\hline & $(-2.07)$ & & $(-1.35)$ & & $(-3.12)$ & \\
\hline \multirow[t]{2}{*}{ Venture dummy } & 0.2698849 & $* \star *$ & 0.1168986 & & -0.3221521 & *** \\
\hline & (4.30) & & $(0.29)$ & & $(-3.50)$ & \\
\hline \multirow[t]{2}{*}{ Underpricing } & 0.0019387 & ** & 0.0026763 & & -0.0001024 & \\
\hline & (2.51) & & $(0.93)$ & & $(-0.09)$ & \\
\hline \multirow[t]{2}{*}{ Proceeds } & 0.01886 & & 0.1309524 & & -0.3959103 & $* * *$ \\
\hline & $(0.43)$ & & $(0.43)$ & & $(-5.61)$ & \\
\hline \multirow[t]{2}{*}{ IPO activity } & 0.0035424 & $* * *$ & -0.0015641 & & 0.0049707 & *** \\
\hline & (2.91) & & $(-0.23)$ & & (2.87) & \\
\hline \multirow[t]{2}{*}{ Age } & -0.0852551 & $* *$ & 0.1560133 & & -0.3153695 & $* * *$ \\
\hline & $(-2.04)$ & & $(0.60)$ & & $(-5.03)$ & \\
\hline \multirow[t]{2}{*}{$\mathrm{E} / \mathrm{A}$} & 0.0117489 & $* * *$ & 0.0122675 & & -0.0214169 & $* * *$ \\
\hline & (6.18) & & $(0.91)$ & & $(-10.33)$ & \\
\hline \multirow[t]{2}{*}{$\mathrm{dA} / \mathrm{A}$} & 0.0029443 & $* * *$ & 0.0011324 & & 0.0021552 & $* * *$ \\
\hline & (6.70) & & $(0.47)$ & & (3.57) & \\
\hline \multirow[t]{2}{*}{ Equity } & 0.0792698 & $* * *$ & 0.2271507 & ** & -0.2696871 & *** \\
\hline & (3.04) & & (2.15) & & $(-6.66)$ & \\
\hline \multirow[t]{2}{*}{ R\&D expense } & 0.0432972 & * & -0.1730271 & & 0.0821518 & $* * *$ \\
\hline & (1.76) & & $(-1.16)$ & & (2.65) & \\
\hline \multirow[t]{2}{*}{ SGA expenses } & 0.0081118 & & -0.0976521 & & 0.0950308 & $* * *$ \\
\hline & $(0.28)$ & & $(-0.74)$ & & (3.07) & \\
\hline \multirow[t]{2}{*}{ Leverage } & 0.0087782 & $* * *$ & 0.0230566 & *** & 0.0392581 & $* * *$ \\
\hline & (7.46) & & (3.27) & & (19.96) & \\
\hline \multirow[t]{2}{*}{ IPO Year (80-84) } & 0.0350091 & & 2.548512 & *** & 1.255527 & \\
\hline & $(0.10)$ & & (5.53) & & (1.29) & \\
\hline \multirow[t]{2}{*}{ IPO Year (85-89) } & 0.2758279 & & & & 1.198326 & \\
\hline & $(0.77)$ & & & & (1.23) & \\
\hline \multirow[t]{2}{*}{ IPO Year (90-94) } & 0.4564393 & & & & 1.111746 & \\
\hline & (1.28) & & & & (1.14) & \\
\hline \multirow[t]{2}{*}{ IPO Year (95-99) } & 0.7222998 & $* *$ & -1.085598 & & 1.783539 & * \\
\hline & $(2.00)$ & & $(-1.26)$ & & $(1.82)$ & \\
\hline \multirow[t]{2}{*}{ IPO Year (00-06) } & 0.6083188 & * & & & 1.869134 & * \\
\hline & (1.68) & & & & $(1.90)$ & \\
\hline
\end{tabular}

${ }^{*},{ }^{* *},{ }^{* * *}$, significant at the 10,5 , and 1 percent level, respectively. 
Figure-1 Cumulative Incidence Function (CIF) for Small, Medium, and Large firms
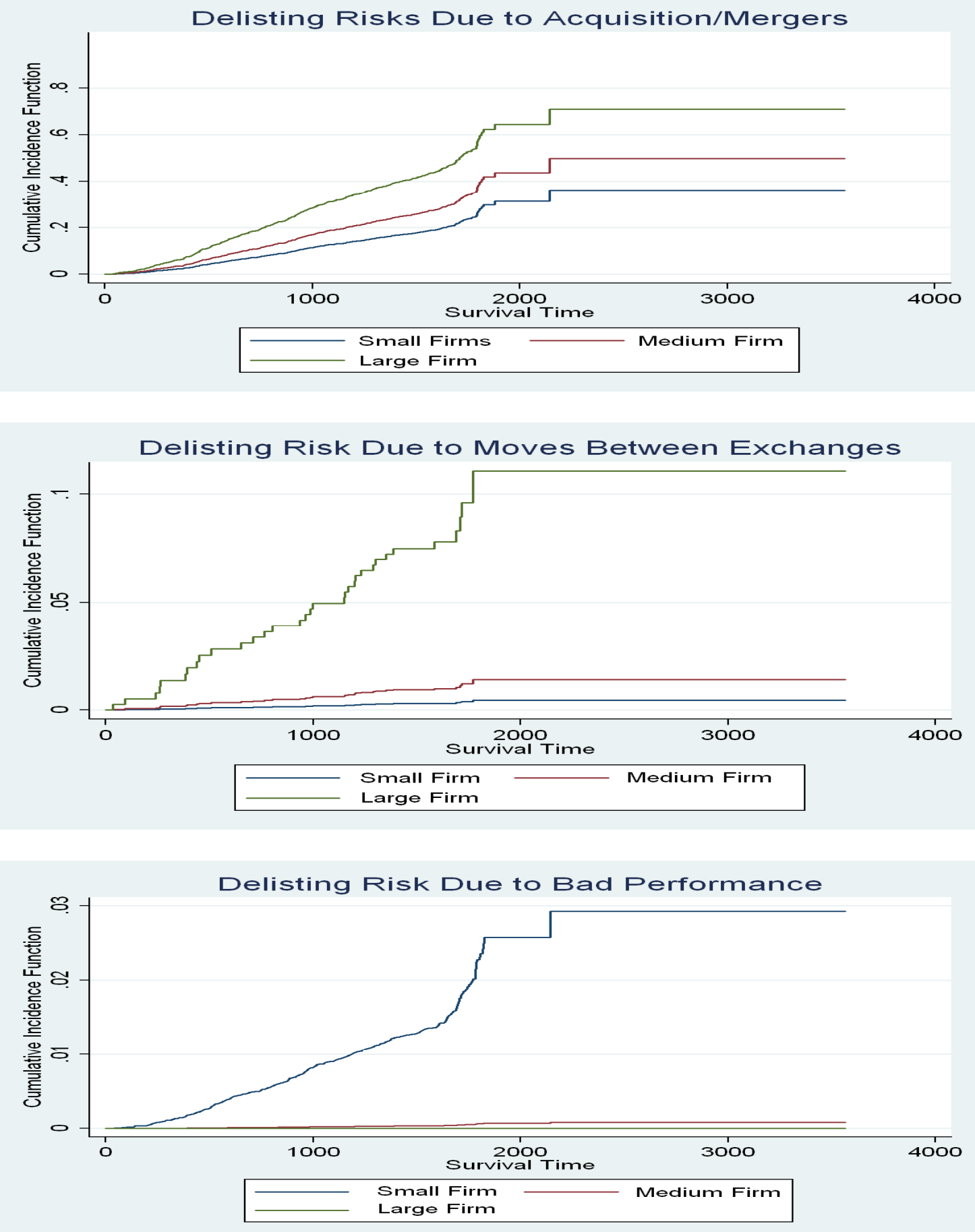